\title{
LOS PROCESOS EDUCATIVOS EN WASLALA, RAAN
}

Fredy Leonel Valiente Contreras ${ }^{[1]}$

\section{Resumen}

Nicaragua, en distintos períodos enfrentó altos índices de analfabetismo. El censo de 1971 reportó el 50.2 \%; con la Cruzada Nacional de Alfabetización, se redujo a 12.6\% según registros oficiales de 1980. En el período neoliberal de 1990 al 2006 se incrementó al 35\%, aun a saber que una educación pertinente ha logrado bienestar y equidad social en países en vías del desarrollo autosustentable.

La crisis en el Sistema Educativo se reflejó en la escasa inversión por estudiante, insuficientes textos y material didáctico, precaria infraestructura; insuficiente formación y remuneración de los docentes.

El objetivo de esta línea basal fue diagnosticar y prescribir el enfoque, metodología y evaluación de las estructuras del pensum académico en los procesos educativos en Waslala que hasta en el 2007 sólo disponía de datos estadísticos.

La metodología fue cualitativa-descriptiva y corte transversal. Se indagó factores de calidad: número y porcentaje de ingreso, abandono y egreso, cobertura, rendimiento académico, metodologías, supervisión y evaluación; asimismo la incidencia sociocultural y geográfica del entorno.

El empirismo docente fue del 60\% hasta el 2002 cuando la URACCAN-Las Minas emprendió la profesionalización. El desafío es coordinar con el Ministerio de Educación y la Pastoral; se facilite la profesionalización a nivel terciario; trazar políticas pertinentes para el área rural, coordinar interinstitucionalmente con el Ministerio de Salud; ampliar la cobertura, aprobar nuevas plazas; facilitar materiales didácticos y sistematizar las experiencias.

Palabras claves: Currículum, metodologías, rendimiento, evaluación, supervisión.

\section{Introducción}

En América Latina y el Caribe la desigualdad social afecta a más de 250 millones de latinoamericanos. Las políticas sociales en salud y educación no es el interés en las políticas públicas del neoliberalismo durante las dos últimas décadas a partir de los 90 en Latinoamérica; paradoja en la comprensión de que la educación es la llave maestra para disminuir la brecha de lo inicuo y brindar oportunidades de movilidad

[1] Profesor universitario en Arte, Letras, Sociología y Filosofía. Editor de URACCAN. fredvaliente@yahoo.com 
social, a través de una oferta que procure a la población igualdad de oportunidades y bienestar integral.

Ante los vertiginosos cambios suscitados en el ámbito mundial, se requiere una educación con pertinencia de contexto que proporcione a la niñez, jóvenes y adultos: alegría, nutrición, conocimientos, habilidades, valores y aptitudes para mejorar la calidad de vida, participación ciudadana plena y responsable en la vida de sus comunidades y nación, para afrontar los desafíos del siglo XXI con expectativas reales de empoderamiento.

En la Costa Caribe nicaragüense, no obstante a la diversidad de sus recursos naturales, prevalece un alto índice de pobreza y crisis en el Sistema Educativo. Antes del triunfo de la Revolución Popular Sandinista en 1979, fue anómalo quien tuvo acceso a la Educación Superior.

Actualmente, entre las Instituciones que afrontan la crisis educativa se encuentra URACCAN, fundada en 1995 en el Triángulo Minero. Orientada especialmente contra el avance de la frontera agrícola y depredación de los Recursos Naturales.

En la década del noventa el Recinto Universitario Las Minas, evoluciona cuantitativa y cualitativamente: ahora tiene Extensiones Universitarias en Rosita, Bonanza y Waslala. Su desempeño profesional se guía hacia el fortalecimiento de la calidad académica, con prestigio en procesos socioculturales en la construcción de la Autonomía e Interculturalidad de la Costa Caribe.

\section{Revisión de literatura}

Las trece (13) monografías de licenciados de la Extensión Universitaria de Waslala en la carrera de Pedagogía con Mención en Ciencias de la Educación. Antes no existía referencia alguna de estudio cualitativo en la temática educativa en el municipio de Waslala.

\section{Metodología y material}

El estudio se realizó en el municipio de Waslala, nominalmente pertenece a las Región Autónoma del Atlántico Norte -RAAN-; pero, administrativamente está centralizado en Matagalpa. Es un análisis semiótico donde se verificaron las variables a través de la reconstrucción de la línea del tiempo, aplicado a trece investigaciones de tipo de corte transversal, descriptiva, cualitativa y participativa. 
En las 13 investigaciones monográficas de los licenciados se implementaron los métodos y técnicas de entrevista, grupos focales, observación directa y análisis documental. El material: computadoras, grabadoras, cassetes, CDS, memorias USB, cámara de video, cámara fotográfica, data show, pantallas, pizarrón, marcadores.

\section{La población de análisis}

En Educación Preescolar: Cincuenta y nueve (59) centros preescolares de los cuales 56 son comunitarios y 3 son formales.

En Educación Secundaria: Ocho (8) centros de estudios que atiende el sistema de Educación Secundaria.

El empirismo docente: En siete centros educativos, tanto en el área urbana como rural.

Programa de Educación Básica de Adultos: Cuarenta y tres círculos de estudio (43) y quinientos noventa y cuatro (594) estudiantes del EBA y ciento quince (115) del ciclo CEDA.

Las escuelas de la Pastoral Educativa: Cincuenta y cuatro (54) escuelas parroquiales y ochenta y tres (83) docentes; dos mil novecientos cincuenta y cinco $(2,955)$ estudiantes.

Población universitaria, 176 estudiantes de la URACCAN.

\section{Resultados y discusión}

\section{Componentes del currículo en pre-escolar}

Los docentes, técnicos y directores de preescolar desconocen los componentes del currículo; pero, el 100\% manifestó que conoce las tres áreas que se desarrollan: psicomotora, socio afectiva y cognitiva.

El 60\% del personal docente aplica metodologías activas mediante la participación en diversas actividades y un $40 \%$ ejerce metodologías tradicionales.

\section{Factores que inciden en la deserción en el preescolar}

$\mathrm{El} 30 \%$ de los docentes atribuye las deserciones a la inmigración temporal de los padres de familia para resolver necesidades económicas; el 20\% a las enfermedades y epidemias ocasionadas por cambios climáticos y contaminación ambiental; el 40\% a la distancia de los centros preescolares que obliga a retirar a la niñez para no exponerlos 
a peligros en invierno; el 10\% de los docentes expresaron que los padres no le dan la debida importancia al preescolar.

El municipio de Waslala cuenta con 59 preescolares de los cuales 56 son comunitarios y 3 son formales.

\section{Calidad docente en la educación preescolar}

Los docentes que atienden la modalidad del preescolar, el $70 \%$ son estudiantes de los niveles de secundaria, el 20\% están integrados a la Escuela Normal y el 10\% son estudiantes de sexto grado de primaria.

La metodología empleada por la mayoría de los docentes no es pertinente, porque no reúne los aspectos psicopedagógicos de acuerdo a las características que comprende la edad de los preescolares.

\section{Resultados en Educación Primaria}

La Educación Primaria desarrollada durante dieciséis años en Waslala entre 1990 al 2006 fue tradicionalista, predominó el dictado, la receptividad y pasividad de los estudiantes.

Desde 1990 hasta 1996, con el gobierno de la señora Violeta Barrios, se determinó el cambio en la administración pública y hacia nuevos programas. Oficializan los textos para Educación Primaria: Barrilete, Azul y Blanco, orientados para las áreas urbanas y por lo tanto, descontextualizados al área rural. Se implementan las capacitaciones mensuales, a través de los Mini Centros de Intercapacitación (MIC), donde se enseñaba a evaluar y planificar a los docentes empíricos: un 90\% a nivel municipal.

En relación a las metodologías, especialmente en primer grado se utilizaba el Método Fónico, Analítico, Sintético (FAS) que desde los años ochenta se ejercía en la Educación Primaria a nivel nacional.

\section{Pertinencia del currículum educativo en Educación Primaria y Secundaria}

En entrevista con la licenciada Toledo, delegada del MED en el municipio de Waslala, explicó que el currículo educativo de Educación Primaria y Secundaria no está contextualizado a las características geográficas, sociopolíticas y culturales del municipio. 


\section{Proyección de coherencia y construcción con visión integral}

Los docentes al referirse al currículo exteriorizaban desconocimiento al mismo, y expresaron que desarrollaron los contenidos propuestos verticalmente en el pensum académico en cada nivel.

Además, se encontró que el programa de contenidos por asignaturas en la modalidad diurna es aplicado en la modalidad nocturna y sabatina, sin abordar un $15 \%$ de los contenidos en la modalidad nocturna y un 30\% en el sabatino. Se excluyen en la modalidad nocturna y educación a distancia, la asignatura de educación física, educación práctica y orientación vocacional.

El plan de estudio mínimo establecido por la Ley General de Educación de Nicaragua, artículo 75 Ley No. 582, sugiere impartir las asignaturas de: Idioma Español, Matemáticas, Idioma Extranjero (inglés), Ciencias de la Naturaleza Física, Química, Biología y Ciencias Naturales, Educación Física, Ciencias Sociales, Historia y Geografía de Centroamérica, Historia Universal, Filosofía, Economía, Formación Cívica y Orientación Vocacional.

En los planes de estudio en Educación Secundaria se cumple con la mayoría de las asignaturas según lo dicta la Ley; sin embargo, no aparecen las asignaturas de economía y filosofía en el nivel de cuarto y quinto año del nivel diversificado, bases fundamentales para la interpretación científica de los fenómenos universales. El plan de estudio de Educación Secundaria a nivel nacional está centralizado en todos los municipios de Nicaragua, es decir no hay adecuación curricular.

\section{Metodologías aplicadas en el proceso enseñanza}

El resultado en tres centros educativos de Educación Primaria y en tres de Educación Secundaria sobre las metodologías aplicadas: de un total de 20 docentes, 8 implementan la metodología pasiva (40\%), 4 colectiva (20\%), 4 deductiva (20\%), 2 heurística (10\%) y 2 activas (10\%). En Educación Primaria: De 20 docentes, 6 aplican la metodología inductiva (30\%), 10 pasiva (50\%), 4 colectiva (20\%).

\section{Entorno en el cual se desarrolla el proceso de enseñanza}

En el área rural son precarias las condiciones para el desarrollo educativo porque no se tiene biblioteca escolar, moblaje, las aulas son pequeñas y el MED hasta el momento sólo garantiza el salario del personal docente. 


\section{Formación profesional}

El Ministerio de Educación implementó capacitaciones cuyo objetivo fue desarrollar habilidades, destrezas y técnicas que permitieran a docentes de Educación Primaria desempeñarse con facilidad a través de la implementación de la Certificación de Actitudes Pedagógicas (CAP), realizadas en el 2000 en la Escuela Normal de Waslala.

\section{La educación rural en el estudio de casos}

En las dos escuelas seleccionadas del área rural: “José Dolores Estrada” y "Emmanuel Mongalo", se describió la atención en la modalidad de multigrado o sea de dos a más grados, los estudiantes reciben clases en situaciones favorables y la infraestructura es adecuada.

\section{Programas de estudio de las escuelas rurales}

En el estudio de casos en las escuelas "José Dolores Estradas" y "Emmanuel Mongalo", los docentes se guían del programa que especifica los contenidos a desarrollar por asignatura; no obstante, responden a un contexto urbano y por consiguiente no tiene pertinencia a un contexto rural, multicultural y plurilingüe.

Los programas no consideran el ciclo de la producción de las familias campesinas de la zona, principalmente de los que emigran a otras zonas a trabajar en los cortes de café, fuente de ingreso de las familias que presentan mayor vulnerabilidad económica y social en el municipio.

\section{Limitantes en las escuelas rurales}

Falta de interés de los padres de familia, un 20\% manifestó que su interés es que sus descendientes aprendan a leer y escribir para que nadie los engañe, y que después de salir de la primaria, sus hijos deberán dedicarse de lleno al trabajo del campo y en cuanto a sus hijas, a trabajar en las tareas domésticas en apoyo a sus madres. Generalmente, sólo el 40\% tienen la oportunidad de estudiar secundaria en el sector urbano del municipio, el $60 \%$ egresados de la primaria rural se quedan en sus comunidades dedicados a labores agrícolas.

\section{Metodología para la enseñanza según los programas}

Los docentes de Educación Secundaria en Waslala, implementan comúnmente la metodología tradicional y es consecuencia del empirismo docente en Educación Primaria y Secundaria. 


\section{EDUCACIÓN}

\section{Evaluación del aprendizaje}

En el calendario escolar del 2006 en Educación Primaria y Secundaria, estableció cuatro evaluaciones parciales por cada semestre para las modalidades diurna, nocturna y también en la modalidad a distancia. Es una evaluación sumativa donde lo que interesa son los resultados numéricos arriba de la nota mínima requerida para cursar el parcial.

\section{Indicadores académicos}

\section{a. Retención y deserción académica}

En Waslala es 'normal' el ingreso de un gran número de estudiantes al iniciar los años lectivos, con el propósito de estudiar en cualquiera de los niveles y modalidades, así resulta que en el 2006, en el nivel de secundaria se obtuvo una matrícula inicial total de 1,506 estudiantes, de los cuales 54\% lo representan mujeres, este dato no difiere comparativamente con el año 2005, de un total de 1,112 ingresados, el 53\% correspondió al sexo femenino de acuerdo a las estadísticas del MECD (2005). Con relación al comportamiento de la matrícula por modalidad, se destaca la Educación a Distancia, con mayores índices de estudiantes al inicio del curso.

\section{b. Rendimiento académico escolar}

En Educación Secundaria en el período del 2006, se obtuvo el $78 \%$ de aprobados y el promedio en la modalidad diurna es del $71 \%$, en la nocturna el $79 \%$ y en la secundaria a distancia supera en $5 \%$ a la nocturna, lo cual indica el mayor índice de rendimiento académico.

Según los docentes la incidencia en el bajo rendimiento de la modalidad diurna es: inasistencia, poca motivación por el hambre, no existe el hábito para el autoestudio, son adolescentes entre los 13 y 15 años con baja autoestima, los padres de familia no participan en las actividades escolares, la implementación de metodologías y tipos de evaluación tradicionalista, las frustraciones por poca comprensión de los contenidos, bajos ingresos económicos en la familia, convirtiéndose estos factores en fracaso escolar.

\section{Percepción docente sobre los factores que inciden en la Educación Secundaria}

El presupuesto económico alcanza para el salario mínimo de los docentes ( $C \$ 2,800.00)$ en Educación Secundaria y genera insatisfacción. Según Castilla, la carrera docente dejó de ser atractiva en Nicaragua debido a que los salarios son los más bajos de Centroamérica, 6o dólares promedio, cuando en el resto de países promedia 200 dólares (http: //www.einuevediario.com.). 
El mismo autor, destaca que "en vista del bajo nivel de salarios, la jornada laboral de 27.5 horas semanales impartiendo clases, permite el doble empleo" (Ibíd.).

\section{Nivel Profesional}

En secundaria el empirismo supera con creces al de primaria habiendo llegado en 2002 al 37\%, y uno de los territorios de Nicaragua con mayor porcentaje de empirismo es la RAAN con el $43 \%$.

\section{Infraestructura y materiales didácticos}

En los centros de Educación Secundaria públicos: "El Naranjo" y la escuela "Rubén Darío", hay sobrepoblación en las aulas de clase, principalmente de primero a tercer año.

Los especialistas señalan que cuantos más estudiantes se tenga en clase más se reduce la probabilidad de participación y recepción de estímulos individuales. También hace falta espacio para la sala de los docentes, biblioteca, dirección, servicios higiénicos, falta de pupitres, escritorios y equipo modernos de investigación.

\section{La evaluación: percepción de la comunidad educativa}

La percepción del 85\% del personal docente catalogó que la evaluación es un instrumento que sirve para calificar los aprendizajes según objetivos mínimos.

El 33\% de los estudiantes expresó que la evaluación es un mecanismo para controlar el aprendizaje y dar una calificación; el 20\% de los padres opinaron lo mismo. El personal de dirección en un 50\% opinaron: "las normativas de evaluación deben revisarse y aplicarse diversificadamente, es necesario reformarlas porque estas no responden a las realidades de cada región y municipio". Tipos de evaluaciones (ver gráfico No. 1).
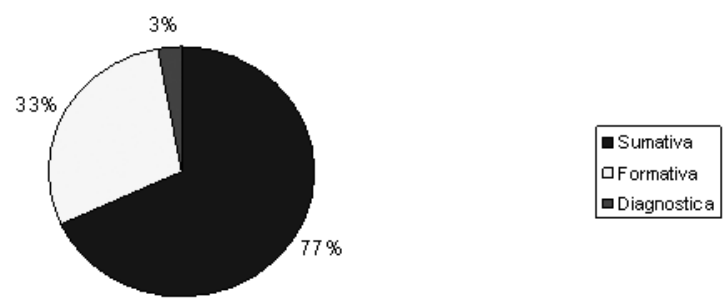

Gráfico No. 1. Tipos de evaluación 


\section{Cobertura y rendimiento académico en la Educación Básica de Adultos -EBA-}

"En Waslala se brindó cobertura desde 1980 después de la Cruzada de Alfabetización bajo la atención de la Pastoral Educativa. Se atendieron treinta y seis (36) comunidades rurales y dos (2) barrios ubicados en el área urbana del municipio". (Entrevista a Rodolfo Sánchez y Leonel Hernández, 5 Diciembre, 2006).

En relación a la organización administrativa, se cuenta con una coordinación y dos técnicos para seguimiento y control. Existen cuarenta y tres (43) círculos de estudio. De los cuales treinta y nueve (39) son de Educación Básica de Adultos -EBA-y cuatro (4) del Centro de Educación de Adulto -CEDA-, con un total de quinientos noventa y cuatro (594) estudiantes correspondientes al EBA.

Es notable el apoyo que han brindado los organismos no gubernamentales en Waslala a la Educación de Adultos como ADRA y AMFVG, con un 53\% de cobertura. La parroquia, a través del proyecto educativo con un 21\% y el Ministerio de Educación (MECD) con un $26 \%$, de los cuales un $18 \%$ han pertenecido al EBA y $8 \%$ al CEDA.

La modalidad es facilitada en tres niveles: El primero equivale al 1ro y 2 do grado de Educación Primaria. En este nivel, los adultos aprenden a leer y escribir y se familiarizan con los conocimientos básicos en las diferentes áreas de estudio.

Segundo nivel, equivale al 3 ro y 4 to grado. Se desarrollan los contenidos de formación general básica. El tercer nivel, equivale al 5 to y 6 to grado. En éste se consolidan los conocimientos básicos iniciados en los niveles anteriores. Una vez alcanzados los aprendizajes propuestos, se le extiende el certificado de Educación Primaria.

\section{Los métodos utilizados en la Educación Básica de Adultos}

El proceso metodológico es el psicosocial, se parte de la observación de una lámina, en ella se identifican los elementos, se reflexiona en torno a las experiencias y realidad del estudiante.

El método de la palabra generadora y de análisis, se inicia con una palabra, que es el eje temático de la unidad, la descomposición de la palabra en sílabas y el estudio de la familia silábica directa.

Por último, el método de síntesis que se efectúa con la combinación de sílabas directas, inversas y complejas para la formación de palabras y la formación de oraciones. Posteriormente se llega a las conclusiones y síntesis, esto se hace a través de los ejercicios de afianzamiento. 


\section{Incidencia de la EBA en el desarrollo personal y comunitario}

Al preguntarles de qué manera les ayudaría el estar en el programa EBA, un $45 \%$ respondió que les podría ayudar a encontrar un empleo. El 60\% a operar un negocio o trabajar por cuenta propia y un $55 \%$ tiene sus esperanzas que al concluir sus estudios puedan buscar otro empleo. Quienes contestaron en buscar otro empleo, en su mayoría fueron mujeres que laboran en el servicio doméstico (Ver gráfico No.2).

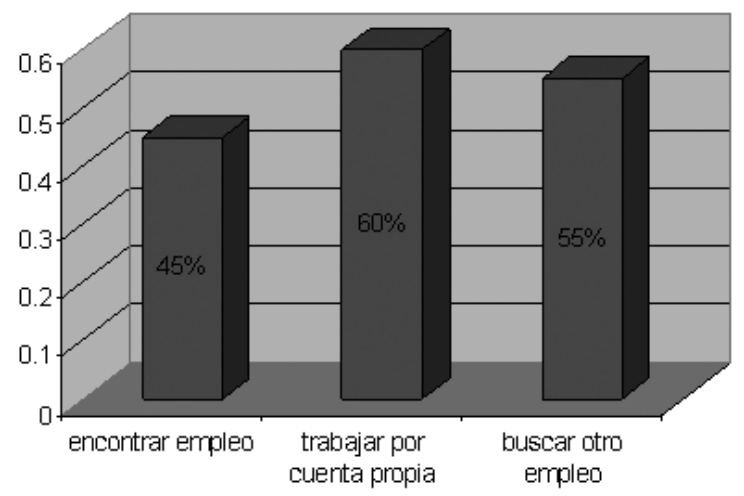

Gráfico No. 2: Opinión en relación a la importancia de estar en el EBA (Fuente: entrevistas a estudiantes del EBA-Waslala, 2006).

\section{Participación social de los estudiantes en el EBA}

La participación en organizaciones y grupos comunales es otra manera en la cual se sienten útiles a su comunidad y por ende contribuye a su autoestima y al fortalecimiento para trazarse metas de competencias más amplias.

La mayoría de la población es de origen campesino, están organizados en un 40\% en grupos productivos de cacao, café, granos básicos y la ganadería entre otros. El 30\% se encuentran organizados en los comités de la iglesia, tanto católica como evangélica. El resto está distribuido en grupos deportivos, musicales, comités de desarrollo comunal y de salud.

Otro aspecto es la transferencia en la vida familiar. Esto se concreta en la ayuda a sus hijos. Manifestándose en una decisión significativa, los padres ayudan en las tareas asignadas en la escuela. 


\section{La calidad de la supervisión en Waslala}

\section{Tipos de supervisión}

Los supervisores enfatizan tres tipos de supervisión: democrática, autocrática y de inspección.

El $100 \%$ de los supervisores desarrollan supervisión de inspección. Los docentes manifestaban que todos los supervisores son extremistas en su autoridad, que les hacen sentirse oprimidos y los amenazan con el despido sino mejoran su trabajo.

Utilizan la misma forma de supervisión: Llegan a la escuela, se sientan y observan la manera de cómo se conduce el proceso de enseñanza, y al finalizar las clases les entregan la ficha de evaluación para que el docente la firme.

Los supervisores no tiene una profesión que amerite los requisitos que demanda la supervisión educativa, razón por la cual desconocen otros tipos de supervisión con relevancia; asimismo las políticas y filosofía del currículum, con mayor énfasis en las prácticas educativas constructivistas, participativas, significativas y socializadoras.

\section{Funciones de la supervisión educativa}

Se comprueba sobre las funciones del supervisor, que enfatizan dos funciones: la administrativa y organizativa. En estas funciones están pendientes de que todos los programas de educación estén completos.

\section{Objetivos de las supervisiones}

Sólo se cumple el objetivo que es evaluar el rendimiento académico del personal docente, el 100\% de los supervisores ponderan lo cuantitativo y desconocen los procesos significativos del enfoque cualitativo en la educación.

Se concluye que la supervisión se limita a:

Observar los cuadernos a los estudiantes para detectar la congruencia entre lo planificado y lo ejecutado.

- Inspeccionan las carpetas a los estudiantes -rincones de aprendizaje-.

- Revisan informes estadísticos: matrícula de rendimiento académico, deserción, asistencia, ausentismo. 


\section{Principales causas que incidieron en el empirismo docente}

- Económicas: Un 70\% expresó que la situación económica fue la causa principal que obstaculizó su profesionalización, los bajos salarios y los altos costos de la vida: transporte, alimento, hospedaje, documentos.

- Geográficas: Antes del año 2003 para profesionalizarse se debía viajar hasta Matagalpa, $241 \mathrm{Km}$., desde el municipio de Waslala.

- Oferta profesional: Según la coordinadora del núcleo normalista de Waslala, en el 2007 egresaron 62 docentes de las Escuelas Normales, estos datos son proporcionales a las cifras enunciadas por Castro (2004 pp.14) de que el promedio de docentes graduados anualmente en las escuelas Normales entre 1998 y 2002 no supera 800 docentes. En los centros de enseñanza en Waslala se obtuvieron los siguientes datos: 61 \% de empirismo en Educación Primaria y 57 \% en Educación Secundaria.

- Gubernamentales: Según los docentes el fondo monetario asignado por los diferentes gobiernos al sector educación, históricamente fue insuficiente. El presupuesto asignado a la educación para el año 2006 fue de 2,770 millones de córdobas y para el año 2007 será de 3,450 millones de córdobas el cual se considera aún insuficiente.

\section{El fortalecimiento de la práctica docente}

\section{Desarrollo profesional}

En Waslala, los Mini Centros de Intercapacitación (MIC), según los técnicos municipales en el período 2002-2003, participaron aproximadamente 313 docentes de las tres categorías de centros, estas acciones tuvieron la asesoría de los estudiantes de pedagogía de la URACCAN. A partir del 2005 los MIC se sustituyeron por las jornadas pedagógicas, en éstas se impartieron talleres sobre las siguientes áreas:

\section{a. Asesoría pedagógica}

El 90\% de los docentes afirmaron que las asesorías pedagógicas se realizaron en los centros educativos; sin embargo, se frecuentaron los centros de categoría "A", con una frecuencia bimensual; en los centros de categoría " $\mathrm{B}$ ", las asesorías fueron semestrales y en los centros de categoría " $C$ " recibieron sugerencias una vez al año por el difícil acceso y falta de interés de los coordinadores y algunos directores de núcleos educativos.

\section{b. Capacitación de formación sistemática}

Las capacitaciones desarrolladas en los últimos años en los países iberoamericanos fueron similares a las antes descritas: informática educativa, metodologías 
activas, dominio del enfoque constructivista y postgrados de actualización científica. Organización de Estados Iberoamericanos (2006).
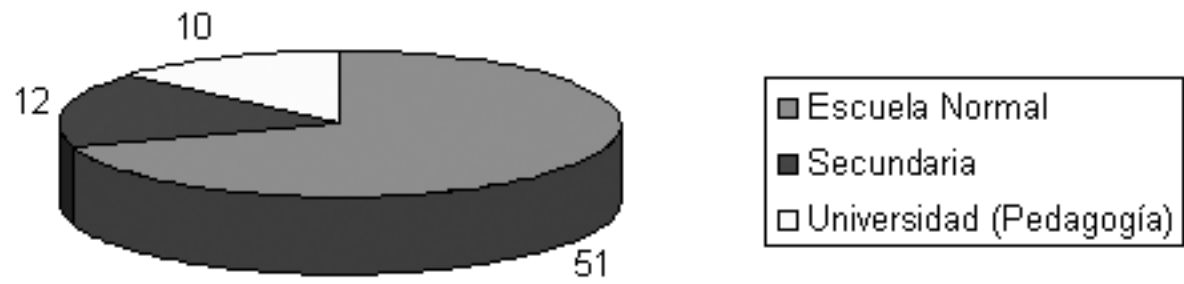

\section{Gráfico 3. Preparación académica del personal docente}

En apoyo a la profesionalización el Ministerio de Educación Cultura y Deportes (2006), en el 2005 impulsó el fortalecimiento de los núcleos de profesionalización en la zona montañosa del centro de Nicaragua: Waslala, río San Juan, Nueva Guinea y El Rama.

\section{Planificación docente}

En la planificación de clases los docentes de multigrado (categoría A) expresaron que utilizaron los tres momentos que orienta el Ministerio de Educación -aprendo, practico y aplico-; empero, un $90 \%$ se limita a las orientaciones de las guías en dicha modalidad y no contrastan los planteamientos teóricos con la realidad que se vive en la comunidad, es decir: escasamente innovan.

\section{Recursos metodológicos}

En los centros de categoría "A" y "B" disponían de programas, guías, estándares educativos y matrices de contenido en el caso de secundaria; los restantes centros educativos disponen únicamente de textos escolares y algunas guías de multigrado, factores que dificultan el desarrollo del proceso educativo con calidad.

En cuanto a metodología se utilizó principalmente el método inductivo y deductivo, técnica de exposición, elaboración de resúmenes y resolución de cuestionarios en equipo.

\section{Evaluación}

Los docentes no graduados aplicaron la evaluación diagnóstica, formativa y sumativa en su mayoría de manera empírica, en espacios y momentos no oportunos, al finalizar el año escolar la reprobación es del 50\%. 


\section{Dominio científico de la asignatura}

El dominio científico respecto a contenidos se consideró deficiente principalmente en Educación Primaria, éstos no se actualizan, no investigan y reproducen temas que caducaron o se restringen a los conceptos del texto y no amplían el área del conocimiento porque desconocen a fondo de qué trata un determinado contenido.

En Educación Secundaria se tiene dominio en las áreas de las Ciencias Sociales y Español; pero, se manifestó debilidad en el área de Inglés, Matemática, Química y Biología, no profundizaron en temáticas de mayor complejidad y otras las obviaron.

\section{Recursos didácticos}

Se utilizan los recursos tradicionales de textos, pizarra, tizas o marcadores. Un 40\% usa pizarras acrílicas, plumones, folletos y en ocasiones medios audiovisuales -retroproyector, multimedia, grabadoras, televisores y DVD- principalmente en los centros de categoría "A". Los centros escolares de categoría "B" usan pizarras acrílicas y de concreto, mapas, láminas para el área de Ciencias Naturales y Estudios Sociales y los textos. Las escuelas de las comunidades que se ubicaron en categoría "C" utilizan pizarrón, tizas y los textos o guías de aprendizaje en los multigrados.

\section{Equidad de género}

Se enfatiza el enfoque de género, pero en la realidad a las niñas no les gusta trabajar con los niños y viceversa. Acarrean estereotipos desde las familias y luego en la escuela tardan en erradicarse. En secundaria la equidad de género es mejor porque los estudiantes en centros urbanos adoptaron una conducta sociable, trato justo entre estudiantes y docentes y ecuanimidad en las tareas escolares.

\section{Atención a la diversidad}

El profesorado enfatiza los problemas que tiene que ver con aspectos curriculares, programas estándares, textos, y dejan en un segundo plano los agentes externos al contexto del aula.

\section{Funcionamiento de la Pastoral Educativa “La Inmaculada”}

En Waslala en el 2006 existían ciento cincuenta y siete (157) escuelas de primaria, de las cuales cincuenta y cuatro (54) fueron dirigidas por la parroquia a través de la Pastoral Educativa. Actualmente en el 2008, existen 211 escuelas. Este trabajo educativo es para atender a las comunidades más pobres y vulnerables, donde el Ministerio de Educación no tiene presencia y se genera empleo a los docentes que laboran en el área educativa. 
La metodología que emplean es participativa, constructivista humanista, activa e inductiva.

\section{Nivel académico de los docentes de la Pastoral Educativa}

De una cantidad de ochenta y tres docentes, sesenta y cuatro se encuentran en los cursos de Educación Primaria y siete se encuentran estudiando en la Universidad "URACCAN".

\section{Pertinencia de las carreras en la Extensión Universitaria de Waslala}

\section{Pertinencia de las carreras implementadas, 2006}

El componente pertinencia se refiere si los criterios valorativos de los programas educativos, los procesos relacionados con el logro de sus contenidos, métodos y resultados, responden a las exigencias del desarrollo individual y social del país, idoneidad para desempeñarse laboralmente de acuerdo al perfil de su carrera.

\section{a. Pertinencia según las autoridades municipales}

El $80 \%$ de las autoridades municipales expresaron que las carreras en Ciencias de la Educación y Ciencias Naturales con mención en Biología, han contribuido al fortalecimiento del Sistema Educativo; igualmente las carreras de Ingeniería Agroforestal e Ingeniería en Zootecnia, porque Waslala es eminentemente agrícola y pecuario, con un alto potencial de desarrollo.

\section{b. Pertinencia según estudiantes de la extensión}

Desde la perspectiva de los estudiantes, el $75 \%$ afirman que las carreras son pertinentes, especialmente en el campo de la educación, seguida del rubro agropecuario. El $17 \%$ opinó que algunas no son pertinentes porque las oportunidades de empleo institucional son escasas en carreras como Administración de Empresa y Ciencias Sociales con mención en Desarrollo Local: porque no existen suficientes organizaciones gubernamentales y no gubernamentales, empresas de bienes y servicios que puedan contratar profesionales para la de las mismas, las existentes se reduce a pequeños negocios que son administrados por sus propietarios (Ver gráfico No. 4). 


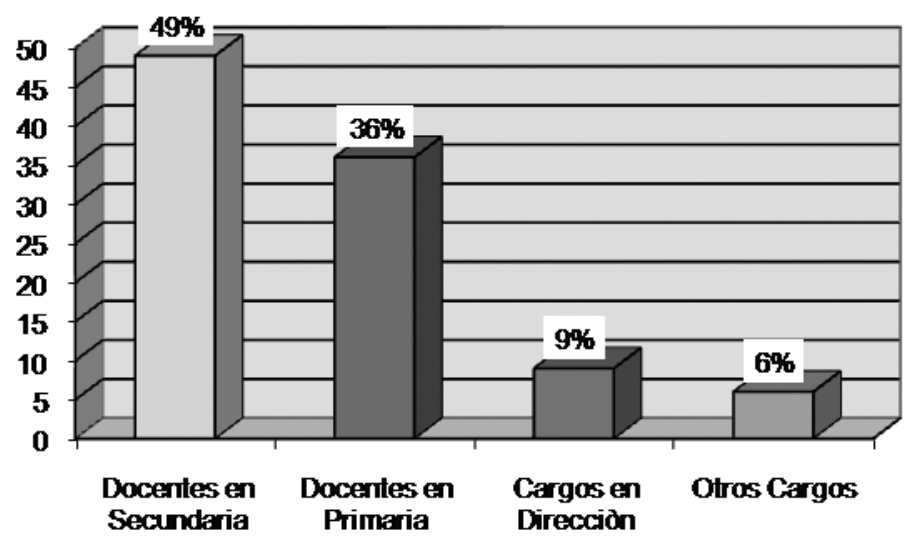

Gráfico No. 4. Graduados en Pedagogía en sus puestos de trabajos 2006

\section{Perfil ocupacional de los graduados en Ciencias Sociales}

Los graduados de la Carrera de Ciencias Sociales con mención en Desarrollo Local, el $29 \%$ se encuentran ubicados laboralmente de acuerdo al perfil de su carrera, $71 \%$ en distintos campos ocupacionales: como directores de centros escolares de Educación Primaria, actividades comerciales y como docentes de Educación Primaria.

\section{La práctica pedagógica de la planta docente de URACCAN en Waslala}

El modelo pedagógico de URACCAN es holístico y está estructurado por diferentes elementos tales como: docencia, estudiantes, currículo, planes de estudios y metodología.

$\mathrm{Al}$ evaluarse la práctica pedagógica de los docentes, el 100\% de los profesores consultados expresaron que cumple con el componente metodológico del modelo, porque aplican el enfoque constructivista humanista, se reconoce al estudiante como sujeto activo quien interactúa con la acción mediadora del docente para lograr un aprendizaje significativo.

Sin embargo, los estudiantes expresaban que el $91 \%$ de los docentes cumplen con el modelo de la URACCAN en referencia a la metodología y cientificidad, enfatizan el espíritu reflexivo en un clima motivador, practican el tacto pedagógico y se percibe la formación humanística y científica. El otro 9\% de los docentes, según su opinión, imparten clases con el modelo tradicional y utilizan el enfoque conductista, emplean actividades como: cuestionarios, conferencias prolongadas, dictados de resúmenes, además olvidan el tacto pedagógico. 
EDUCACIÓN

\section{Percepción del currículum de estudio}

El currículum tiene un 90\% de aceptación. Las asignaturas facilitan los conocimientos y herramientas necesarias para enfrentarse al campo laboral una vez egresado de la URACCAN.

Excepto un $10 \%$ de los estudiantes no está de acuerdo con la inclusión de la asignatura del lenguaje mayangna en los programas de estudios, debido a la visión, porque el contexto es monocultural.

\section{Modalidad, cobertura, rendimiento académico y retención}

En la oferta académica, la Extensión Universitaria de Waslala estableció la modalidad de encuentro sabatino, en las que se ubican las carreras de Ciencias Sociales con mención en Desarrollo Local, Administración de Empresa, Ingeniería Agroforestal e Ingeniería Zootecnia que están dirigidas al personal de Instituciones del MINSA y del MINED, así como a personas que viven en zonas rurales del municipio dedicado a actividades productivas tanto agrícolas como pecuarias.

La modalidad por encuentro es semestral, y se ubican las carreras de Pedagogía y Biología dirigida especialmente a docentes que laboran en los programas de Educación Primaria y Secundaria. La atención en esta modalidad se realiza en período vacacional, atendiendo las características del trabajo que desempeñan los docentes.

Los estudiantes manifestaban que existen necesidades tales como: la instalación de instrumentos de laboratorio, especialmente en las carreras de Ingeniería Agroforestal, Ingeniería en Zootecnia y Licenciatura en Ciencias Naturales con mención en Biología. La infraestructura propia de la Extensión Universitaria, la dotación de medios tecnológicos accesible a los estudiantes.

\section{Conclusiones generales}

\section{En Educación Preescolar}

Los factores principales en la deserción escolar de la niñez son las enfermedades, poco interés de los padres de familia, cambios de domicilio, inestabilidad de los docentes, falta de adaptación de los educandos en las aulas de clase.

\section{En Educación Primaria}

La Educación Primaria en el período 1990 al 2006 fue tradicionalista y empírica. 


\section{Metodologías aplicadas}

Las metodologías utilizadas son variadas, en los seis centros de estudio de Educación Primaria y Secundaria del área urbana y rural: inductivas, pasivas, colectivas, deductivas, heurísticas y activas. Para su implementación proceden con trabajo de equipo, en parejas, individual, investigaciones, debates, exposiciones, ensayos, dramatizaciones y dictados.

\section{Las evaluaciones}

Se practica la evaluación diagnóstica, formativa y sumativa; empero, predomina la sumativa, porque se orienta para aseverar el alcance de los objetivos propuestos en su planificación.

\section{Rendimiento académico en las escuelas primarias del área rural y urbana}

En la Educación Primaria, período escolar 2006, incidieron los factores: falta de hábito de estudio, las exigencias del trabajo en los períodos de cosecha, los factores climáticos afectan debido a los malos caminos y cruces de ríos. Ausencia de material didáctico y libros de textos principalmente en $4^{\circ}, 5^{\circ}$ y $6^{\circ}$ grado. El Ministerio de Educación a través del Programa Integral de Nutrición Escolar (PINE) suministró alimentación a los estudiantes de Educación Primaria lo que permitió fortalecer el rendimiento académico y la retención escolar.

\section{Programa de Educación Básica de Adultos -EBA-}

La EBA tiene cobertura en treinta y seis comunidades rurales y dos barrios en el área urbana. La cobertura es posible gracias al apoyo de la parroquia, a través de la Pastoral Educativa y los organismos APRA y AMFVG y el MECD. Se atiende a una cantidad de treinta y nueve círculos de estudios en la modalidad EBA.

\section{La Supervisión Educativa}

Los supervisores desconocen los tipos, objetivos, técnicas y principios de la supervisión, porque no han tenido oportunidad y/o interés en la apropiación de una supervisión científica con visión profesional.

\section{El empirismo docente en Waslala}

Entre las causas están los bajos salarios y el difícil acceso por las condiciones geográficas fueron las principales condicionantes del poco avance en titulación en el municipio, son más los jóvenes que ingresan a la entidad educativa sin título que los docentes que egresan de las Escuelas Normales. 
El índice de empirismo docente fue muy significativo en el año 2006, éste representó un $61 \%$ en el programa de primaria y un $57 \%$ en secundaria. El mismo disminuyó con el programa de secundaria promovido por la URACCAN, de los 48 docentes empíricos que laboraban en el 2005; 17 egresaron como técnico superior en pedagogía, y se logró reducir el empirismo hasta un $65 \%$.

\section{En Educación Universitaria}

Las autoridades municipales, docentes y estudiantes, coinciden en afirmar que las carreras implementadas en la extensión Waslala, son pertinentes, se destaca en primer orden las carreras en Ciencias de la Educación, seguida de Ingeniería Agroforestal, Ingeniería Zootecnia y las carreras de Ciencias Sociales con mención en Desarrollo Local.

\section{Recomendaciones}

\section{En Educación Preescolar}

Se le recomienda al MED elaborar un plan de capacitación permanente para actualizar a los docentes en relación a las estrategias de aprendizaje en la Educación Preescolar. Reforzar la participación de la planta técnica, dirección, madres y padres de familia para mejorar el funcionamiento de los preescolares mediante el intercambio de experiencias.

A la alcaldía municipal que apoyen los proyectos de infraestructura que favorezcan las condiciones ambientales de los preescolares.

\section{En Educación Primaria}

En la contratación a docentes seleccionar a los que tengan vocación, implementar un programa de capacitación profesional y orientar al personal de dirección que permita la profesionalización de los docentes.

\section{En la evaluación educativa}

Establecer programa de intercambio de experiencia entre directores, docentes, estudiantes, madres y padres de familia, con el fin de reconstruir colectivamente la percepción de la evaluación y unificar criterios.

\section{En políticas educativas para el área rural}

Garantizar nuevas políticas para el área rural y programas adecuados a la realidad de las familias campesinas; elaborar un plan de emergencia educativa para el incremento 
de la cobertura escolar en Educación Primaria, trazando metas concretas, cualitativas y cuantificables.

\section{Al personal docente}

Establecer coordinaciones directas con el Ministerio de Salud (MINSA), para resolver la problemática de enfermedades que se presentan por factores climatológicos y que afectan a la población estudiantil.

\section{Personal de dirección y docentes}

Monitorear la aplicación de las diversas formas de evaluación, a través de la aplicación de técnicas efectivas y que se fomente la auto-evaluación, co-evaluación, metaevaluación y para-evaluación, con el fin de fomentar una evaluación significativa, formativa y democrática.

\section{A las madres y padres de familias}

Un llamado para que participen en los talleres que el Ministerio de Educación sobre la participación comunitaria y sus funciones en el proceso de la enseñanza.

\section{A los directores y subdirectores}

Que promuevan la realización de seminarios, talleres de capacitación y acompañamientos pedagógicos a la planta docente para que apliquen las metodologías con enfoque humanista y constructivista.

\section{A los técnicos del MED}

Profesionalizar a los docentes que atienden los distintos niveles educativos a un nivel universitario, promover la capacitación y acompañamiento pedagógico a los directores, subdirectores y docentes sobre los enfoques educativos con metodologías activas.

\section{Recomendaciones para Educación Secundaria}

Que la delegación municipal soliciten a la sede departamental del MED, la obtención del currículo de Educación Secundaria, para facilitárselo a los docentes que trabajan en diferentes modalidades y niveles.

\section{A la Dirección General de Desarrollo Educativo del Ministerio de Educación}

Implementar una mayor cobertura en la Educación Secundaria a distancia en las comunidades de mayor concentración poblacional: La Posolera, Kaskita Central, Kubali 
Central, Zapote Kun, Arenas Blancas, Ocote Tuma, Waslalita, El Naranjo, principalmente en I y II año. Asimismo, brindar educación gratuita en la modalidad diurna en los centros escolares del sector urbano como la escuela "José Dolores Estrada", disminuir las cuotas arancelarias en el centro subvencionado "Estrella de Belén" y la aprobación de nuevas plazas magisteriales en educación.

\section{El rendimiento académico de la escuela de Educación Primaria}

Se recomienda garantizar los libros de textos y material didáctico, seguir implementado los CAP y gestionar planes de becas para los docentes que ingresan a la universidad. A los docentes realizar planes remediables para la nivelación del aprendizaje de la niñez que no asiste de manera permanente a clase por los diversos problemas: económicos, climatológicos y enfermedades.

\section{Educación Básica de Adultos}

Al MED que garanticen materiales didácticos, gestionar presupuesto para los facilitadores voluntarios a fin de incentivarlos y capacitarlos en las diferentes modalidades o programas de educación. Así mismo, atender prioritariamente las necesidades educativas da las comunidades en situación de pobreza, grupos sociales marginados y con necesidades educativas específicas.

\section{La Supervisión Educativa}

Capacitar a los técnicos y directores sobre la temática de la supervisión escolar. Formar los cuadros a un nivel de Educación Universitaria, a fin de lograr los estándares en la calidad educativa en la región centroamericana. Asimismo, contemplar a mediano plazo una política de incentivos salariales a los docentes empíricos que concluyan la profesionalización y exigir a los profesionales de otras carreras que adquieran las calidades académicas en las carreras educativas y determinar plazos para lograrlo y condicionar sus contratos.

\section{En la profesionalización docente}

A las autoridades de URACCAN que continúen ofertando la carrera en Ciencias de la Educación. Al Ministerio de Educación que coordine con otras instituciones sociales y ONG's parar elaborar y ejecutar líneas de acción que incentiven y faciliten a los docentes la integración a los cursos de profesionalización. 


\section{Para las escuelas de la Pastoral Educativa}

Al Ministerio de Educación que en su presupuesto nacional incluya las Escuelas de la Pastoral Educativa, para proporcionarle materiales didácticos a la niñez, completar el pago de los docentes como lo establece la Constitución de la República.

\section{Para la extensión universitaria de Waslala}

- Al Recinto Universitario Las Minas, apoyar la Extensión Universitaria de Waslala y coordinar con el MED y la Pastoral Educativa, las formas de realizar la profesionalización con un sentido de equidad donde las comunidades rurales tengan los mismos derechos que aquellas del casco urbano, a fin de establecer centros de convergencia universitaria donde puedan asistir la mayoría de los docentes empíricos.

- Brindar seguimiento a su personal docente en sus prácticas pedagógicas, para revertir el 9\% que categoriza la comunidad estudiantil de no facilitar el enfoque constructivista y de faltar al tacto pedagógico, moral y ético.

- Al coordinador de la Extensión Universitaria de Waslala, suspender la calendarización de encuentros los días viernes, porque afecta a personal trabajador de las instituciones.

- A las autoridades de la Extensión Universitaria de Waslala que tengan mayor comunicación con la comunidad estudiantil y una estrategia de motivación como cuadro de honor para estudiantes sobresalientes, estímulos morales o materiales, asambleas con la población estudiantil, con el fin de mantener un alto rendimiento académico.

\section{Lista de referencias}

Araúz Arancibia, Margine \& Muñoz Manzanares, Cándida Rosa (2006). Educación Básica de Adultos en el Municipio de Waslala. Monografía de la licenciatura en Pedagogía con mención en Ciencias de la Educación. Waslala, Región Autónoma Atlántico Norte, Nicaragua. URACCAN. Sin publicar.

Alaniz Talavera, Gumercindo de Jesús \& Espino López, José Miguel (2006). Rendimiento académico, Deserción escolar y Formación Profesional de los docentes de la escuela primaria rural: "Paso de Lajas" en el Municipio de Waslala. Monografía de la 
licenciatura en Pedagogía con mención en Ciencias de la Educación. Waslala, Región Autónoma Atlántico Norte, Nicaragua. URACCAN. Sin publicar.

Blandín García, Félix Pedro \& Muñoz Quintero, Joel Antonio (2006). Supervisión Educativa en los Colegios de Secundaria: "Estrella de Belén", "Rubén Darío" y "La Posolera" en el Municipio de Waslala. Monografía de la licenciatura en Pedagogía con mención en Ciencias de la Educación. Waslala, Región Autónoma Atlántico Norte, Nicaragua. URACCAN. Sin publicar.

Blandón Montenegro, Juana del Carmen \& Amador Jarquín, William (2006). Empirismo Docente en el Municipio de Waslala. Monografía de la licenciatura en Pedagogía con mención en Ciencias de la Educación. Waslala, Región Autónoma del Atlántico Norte, Nicaragua. URACCAN. Sin publicar.

González Tinoco, Dalila \& López Hernández, Flavia (2006). La Educación Preescolar en el Municipio de Waslala. Monografía de la licenciatura en Pedagogía con mención en Ciencias de la Educación. Waslala, Región Autónoma Atlántico Norte, Nicaragua. URACCAN. Sin publicar.

González Flores, Daisy Urania \& Mendoza Pérez, Lidia (2006). Escuelas de la Pastoral Educativa Parroquia "La Inmaculada", Municipio de Waslala. Monografía de la licenciatura en Pedagogía con mención en Ciencias de la Educación. Waslala, Región Autónoma Atlántico Norte, Nicaragua. URACCAN. Sin publicar.

Jiménez Gómez, Rafael \& González, Ramón de Jesús (2006). Caracterización del Desarrollo de la Educación Superior en el Municipio de Waslala. Monografía de la licenciatura en Pedagogía con mención en Ciencias de la Educación. Waslala, Región Autónoma Atlántico Norte, Nicaragua. URACCAN. Sin publicar.

Jarquín Ochoa, Bismarck \& Gaitán Tórrez, Enoe (2006). Autonomía escolar en los Colegios: "Rubén Darío" y "Paso de Laja" del Municipio de Waslala. Monografía de la licenciatura en Pedagogía con mención en Ciencias de la Educación. Waslala, Región Autónoma Atlántico Norte, Nicaragua. URACCAN. Sin publicar.

Mairena Jarquín, María Elsa \& Zeledón Díaz, Gloria Maritza (2006). Prácticas Evaluativas en la Docencia de Educación Secundaria, Colegios: "Rubén Dario" y "Estrella de Belén" en el Municipio de Waslala. Monografía de la licenciatura en Pedagogía con mención en Ciencias de la Educación. Waslala, Región Autónoma Atlántico Norte, Nicaragua. URACCAN. Sin publicar.

Ramírez López, Bertha Adilia \& Montoya Ochoa, Saturnino (2006). Las corrientes pedagógicas que incidieron en el desarrollo de la Educación primaria en los períodos comprendidos entre 1990 y 2,000, en el Colegio Autónomo "Rubén Dario" 
Municipio de Waslala. Monografía de la licenciatura en Pedagogía con mención en Ciencias de la Educación. Waslala, Región Autónoma Atlántico Norte, Nicaragua. URACCAN. Sin publicar.

Úbeda Osegueda, Edman Noel \& Osegueda Lanzas, Lucrecia Ramona (2006). Metodologías del Proceso Enseñanza-Aprendizaje en los Centros Educativos del Municipio de Waslala. Monografía de la licenciatura en Pedagogía con mención en Ciencias de la Educación. Waslala, Región Autónoma Atlántico Norte, Nicaragua.URACCAN. Sin publicar.

Vargas Cruz, Maria del Socorro \& Centeno Hernández, Migdalia (2006). Situación Educativa de las Escuelas de Primaria Rural: "José Dolores Estrada" y "Emmanuel Mongalo" en el Municipio de Waslala. Monografía de la licenciatura en Pedagogía con Mención en Ciencias de la Educación. Waslala, Región Autónoma Atlántico Norte, Nicaragua. URACCAN. Sin publicar.

Zeledón Díaz, Ángel de Jesús \& González Díaz, Denis Asusano (2006). Situación de la educación secundaria en las escuelas: "Rubén Dario", "Estrella de Belén" y "El Naranjo", del Municipio de Waslala. Monografía de la licenciatura en Pedagogía con mención en Ciencias de la Educación. Waslala, Región Autónoma Atlántico Norte, Nicaragua. URACCAN. Sin publicar. 